\title{
Produção de protoplastos e lise da parede celular de leveduras utilizando $\beta-1,3$ glucanase
}

\author{
Protoplasts production and yeast cell wall lysis using $\beta-1,3$ glucanase
}

Luciana Francisco FLEURI ${ }^{1 *}$, Hélia Harumi SATO ${ }^{1}$

\begin{abstract}
Resumo
O presente trabalho visou a aplicação da $\beta-1,3$ glucanase lítica, obtida do microrganismo Cellulosimicrobium cellulans 191, na produção de protoplastos e na lise da parede celular de leveduras. A preparação bruta da enzima foi capaz de lisar as leveduras Kluyveromyces lodderi, Saccharomyces cerevisiae (Fleischmann e Itaiquara), S. cerevisiae KL-88, S. diastaticus NCYC 713, S. cerevisiae NCYC 1001, Candida glabrata NCYC 388, Kluyveromyces marxianus NCYC 587 e Hansenula mrakii NCYC 500. A $\beta-1,3$ glucanase purificada foi capaz de lisar as leveduras Saccharomyces cerevisiae KL-88, Saccharomyces capensis, Debaromyces vanriji, Pachysolen tannophillus, Kluyveromyces drosophilarum, Candida glabrata, Hansenula mrakii e Pichia membranaefaciens e formar protoplastos de Saccharomyces cerevisiae KL-88.

Palavras-chave: $\beta-1,3$ glucanase; protoplastos; leveduras.
\end{abstract}

\begin{abstract}
The aim of this work was the application of lytic $\beta-1,3$ glucanase obtained from Cellulosimicrobium cellulans strain 191 in the production of protoplasts and lysis of yeast cell walls. The crude extract demonstrated lysis activity against the yeasts Kluyveromyces lodderi, Saccharomyces cerevisiae (Fleischmann and Itaiquara), S. cerevisiae KL-88, S. diastaticus NCYC 713, S. cerevisiae NCYC 1001, Candida glabrata NCYC 388, Kluyveromyces marxianus NCYC 587, and Hansenula mrakii NCYC 500. The purified $\beta-1,3$ glucanase demonstrated lysis activity against the yeasts Saccharomyces cerevisiae KL-88, Saccharomyces capensis, Debaromyces vanriji, Pachysolen tannophillus, Kluyveromyces drosophilarum, Candida glabrata, Hansenula mrakii, and Pichia membranaefaciens, and it was able to produce Saccharomyces cerevisiae KL-88 protoplasts. Keywords: $\beta-1,3$ glucanase; protoplasts; yeasts.
\end{abstract}

\section{Introdução}

Enzimas líticas são enzimas envolvidas na lise da parede celular de leveduras e fungos, podendo ser utilizadas para a obtenção de diferentes produtos intracelulares e/ou ligados à célula e para o biocontrole de microrganismos patogênicos.

Com auxílio da lise enzimática, podem ser obtidos peptídeos, proteínas recombinantes, ácidos nucleicos, pigmentos, enzimas e lipídios (FLEURI; SATO, 2007). As enzimas líticas podem ainda ser aplicadas na obtenção de fonte de proteína unicelular para animais e humanos (FLEURI; SATO, 2005) e para a preparação de protoplastos de leveduras e fungos para fusão e transformação celular de microrganismos (SALAZAR; ASENJO, 2007). Estudos também têm sido conduzidos na extração enzimática do polissacarídeo $\beta$-glucana da parede celular das leveduras, o qual apresenta atividades antivirais, bacterianas, fúngicas e contra tumores, além de ser utilizado para aplicação cosmética e na indústria de alimentos saudáveis como estimulador do sistema imune (KIM et al., 2006).

Muitos microrganismos são capazes de produzir enzimas que lisam a parede celular de leveduras (FLEURI; SATO, 2008). As principais enzimas envolvidas na lise de leveduras são $\beta$-1,3 glucanases, $\beta$-1,6 glucanases, mananases, proteases e quitinases, uma vez que a parede é composta principalmente pelos polímeros $\beta$-1,3 glucana, $\beta$-1,6 glucana, mananaproteínas e pouca quantidade de quitina (FLEURI, 2006).

Essas enzimas agem sinergicamente na lise da parede celular, mas somente duas são essenciais para o rompimento da célula: a protease lítica específica, que degrada a camada externa de mananaproteína, e a $\beta-1,3$ glucanase lítica, que degrada a camada interna de glucana (FLEURI, 2003).

As glucanases podem, dependendo da massa molecular e da conformação tridimensional da enzima, lisar células de leveduras sem a presença de protease e outros produtos que exerçam o papel de hidrólise da camada externa de mananaproteína (GUILLOUX-BENATIER et al., 2000).

O microrganismo Cellulosimicrobium cellulans, mencionado como Cellulomonas cartae por Fleuri (2003), Cellulomonas cellulans por Ferrer et al. (1996), Oerskovia xanthineolytic por Ventom e Asenjo (1991) e Arthrobacter luteus por Doi, K., Doi, A. e Fukui (1973), é produtor de um complexo enzimático lítico formado por várias isoformas de $\beta-1,3$ glucanases

Recebido para publicação em 19/6/2008

Aceito para publicação em 16/5/2009 (003596)

${ }^{1}$ Laboratório de Bioquímica de Alimentos, Departamento de Ciência de Alimentos, Faculdade de Engenharia de Alimentos, Universidade Estadual de Campinas - UNICAMP,

Rua Monteiro Lobato, 80, CP 6121, CEP 13083-862, Campinas - SP, Brasil,E-mails: luciana@fea.unicamp.br; luciana@ibb.unesp.br

${ }^{*}$ A quem a correspondência deve ser enviada 
(FERRO, 2002; SOARES, 2002; FLEURI, 2003, 2006). Pode ainda produzir proteases (SANTOS, 2004; FLEURI, 2003, 2006) e quitinases (YAMAGUCHI, 2003; FLEURI, 2003, 2006) em meios de cultivo contendo diferentes indutores.

O presente trabalho visou a aplicação das preparações brutas e purificadas de $\beta-1,3$ glucanase da linhagem Cellulosimicrobium cellulans 191 na lise de leveduras e formação de protoplastos.

\section{Material e métodos}

\subsection{Aplicação da $\beta-1,3$ glucanase na lise de leveduras}

A capacidade da $\beta-1,3$ glucanase bruta de lisar a parede celular de leveduras foi testada com as células viáveis de Kluyveromyces lodderi, Saccharomyces cerevisiae (Fleischmann e Itaiquara), S. cerevisiae KL-88, S. diastaticus NCYC 713, S. cerevisiae NCYC 1001, Candida glabrata NCYC 388, Kluyveromyces marxianus NCYC 587 e Hansenula mrakii NCYC 500. A preparação purificada da enzima foi testada com células viáveis de Saccharomyces cerevisiae KL-88, Saccharomyces capensis, Debaromyces vanriji, Pachysolen tannophillus, Kluyveromyces drosophilarum, Candida glabrata, Hansenula mrakii e Pichia membranaefaciens. As preparações bruta e purificada de $\beta-1,3$ glucanase da linhagem Cellulosimicrobium cellulans 191 foram obtidas como descrito por Fleuri (2006) e Fleuri e Sato (2007).

\subsection{Obtenção das suspensões de células de leveduras}

Para a obtenção de células de leveduras, uma alçada das culturas de leveduras crescidas em tubos inclinados de meio YEPD composto de $1 \%$ de extrato de levedura, $2 \%$ de peptona, $2 \%$ de glicose e $2 \%$ de ágar foi transferida para frascos Erlenmeyer de $250 \mathrm{~mL}$ contendo $50 \mathrm{~mL}$ de meio YEPD líquido. Os frascos foram incubados em agitador rotatório a $30{ }^{\circ} \mathrm{C}, 100 \mathrm{rpm}$ por 20 horas. As células foram coletadas por centrifugação a $7.840 \times$ g por 10 minutos a $5^{\circ} \mathrm{C}$ e lavadas duas vezes com água destilada. Estas células foram ressuspendidas em tampão fosfato $0,1 \mathrm{M}, \mathrm{pH} 6,5$ até se obter uma suspensão com densidade ótica igual a 1,68 a $660 \mathrm{~nm}$.

\subsection{Determinação da atividade lítica}

A atividade de lise foi determinada segundo o método de Ventom e Asenjo (1991) modificado. A mistura para lise enzimática de células de leveduras continha $1 \mathrm{~mL}$ de suspensão celular com densidade ótica igual a 1,68 a $660 \mathrm{~nm}$, enzima bruta ou purificada e tampão fosfato $0,1 \mathrm{M}, \mathrm{pH} 6,5$ para completar o volume para $2 \mathrm{~mL}$.

Para a lise de leveduras com $\beta-1,3$ glucanase bruta ou purificada, a mistura de reação contendo $0,1 \mathrm{U}$ da enzima. $\mathrm{mL}^{-1}$ de suspensão foi incubada a $30{ }^{\circ} \mathrm{C}$ por 1 hora, no caso da preparação bruta, e durante 3 horas, no caso da preparação purificada, sob agitação em intervalos de tempos regulares. Simultaneamente, foi preparado, como referência, um tubo branco onde, no lugar da solução enzimática, foi acrescentado tampão fosfato $0,1 \mathrm{M}, \mathrm{pH} 6,5$.
A atividade lítica foi determinada pela diminuição da turbidez da suspensão de levedura e calculada por modificação do método descrito por Obata et al. (1977) através das Equações 1, 2 e 3:

DO Branco T0' - DO Branco T60' = X

DO Amostra T0’ - DO Amostra T60’ = Y

Absorbância obtida $=\mathrm{Y}-\mathrm{X}$

Uma unidade de liticase foi definida como a diminuição de 0,1 unidades de absorbância nas condições de ensaio a $660 \mathrm{~nm}$ e descritas neste artigo como atividade relativa.

\subsection{Observação em microscópio óptico da lise de leveduras}

As leveduras foram incubadas com $\beta-1,3$ glucanase purificada $\left(0,1 \mathrm{U} \cdot \mathrm{mL}^{-1}\right.$ de suspensão) a $30^{\circ} \mathrm{C}$ por 3 horas e a lise foi observada em microscópio óptico com aumento de 1000 vezes (imersão). Como controle, utilizaram-se leveduras em tampão sem adição da enzima, incubadas no mesmo tempo e temperatura.

\subsection{Aplicação da $\beta-1,3$ glucanase purificada na formação de protoplastos}

As células da levedura Saccharomyces cerevisiae KL-88, obtidas como descrito anteriormente, foram coletadas por centrifugação e ressuspendidas em uma solução estabilizadora osmótica de $\mathrm{KCl}$ 0,7 M em tampão fosfato 0,1 M, pH 6,5. A mistura de reação, contendo $1 \mathrm{~mL}$ da suspensão de levedura com densidade ótica igual a 1,68 a $660 \mathrm{~nm}$ e $0,1 \mathrm{U}$ de $\beta-1,3$ glucanase purificada. $\mathrm{mL}^{-1}$ de suspensão, foi incubada a $30^{\circ} \mathrm{C}$ por 2 horas, e a formação de protoplastos foi observada em microscópio óptico com aumento de 1000 vezes (imersão). Como controle, foi utilizada mistura de reação, contendo as leveduras em solução estabilizadora osmótica sem a adição da enzima, incubada no mesmo tempo e temperatura.

\section{Resultados e discussão}

\subsection{Aplicação da preparação bruta de $\beta-1,3$ glucanase na lise de leveduras}

A preparação bruta de $\beta-1,3$ glucanase da linhagem C. cellulans 191 foi capaz de lisar as linhagens de Kluyveromyces lodderi, S. cerevisiae (Fleischmann), S. cerevisiae (Itaiquara), S. cerevisiae KL-88, S. diastaticus NCYC 713, S. cerevisiae NCYC 1001, Candida glabrata NCYC 388, Kluyveromyces marxianus NCYC 587 e Hansenula mrakii NCYC 500, sendo que as linhagens K. marxianus NCYC 587 e H. mrakii NCYC 500 mostraram-se mais sensíveis à $\beta-1,3$ glucanase quando comparadas com a susceptibilidade da linhagem de S. cerevisiae KL-88. As linhagens de leveduras S. cerevisiae (Itaiquara) e C. glabrata NCYC 388 mostraram-se mais resistentes à ação da $\beta-1,3$ glucanase.

Foram obtidas atividades líticas relativas de 46,97; 49,89; 36,$53 ; 40,6 ; 45,2 ; 40,50 ; 29,64 ; 74,0$; e $100,0 \%$, respectivamente sobre as leveduras Kluyveromyces lodderi, S. cerevisiae 
(Fleischmann), S. cerevisiae (Itaiquara), S. cerevisiae KL-88, S. diastaticus NCYC 713, S. cerevisiae NCYC 1001, Candida glabrata NCYC 388, Kluyveromyces marxianus NCYC 587 e Hansenula mrakii NCYC 500.

Diversos pesquisadores relataram que, para a lise da parede celular, a protease deve atuar primeiro (FUNATSU et al.,1978; KITAMURA, 1982; OBATA, 1977), ou que as enzimas líticas (proteases e $\beta$-1,3 glucanases) devem agir sinergicamente na lise da parede celular, sendo que as proteases degradam a camada externa de mananaproteína e as $\beta-1,3$ glucanases degradam a camada interna de glucana (SCOTT; SCHEKMAN, 1980; ZLOTNIK et al., 1984; ASENJO et al., 1985; SHIMOI et al., 1991).

O presente estudo revela que a preparação bruta de $\beta-1,3$ glucanase obtida da linhagem C. cellulans 191 foi capaz de lisar diferentes gêneros de leveduras sem a necessidade de proteases ou quaisquer outros produtos que exerçam a função de destruição da camada externa de mananaproteína como cisteína e $\beta$-mercaptoetanol.

A divergência da atividade de lise das leveduras estudadas é explicada pela diferença da composição e da organização da parede celular desses microrganismos. Segundo Cabib et al. (1997), a parede celular de leveduras não é uma estrutura estática e sim uma estrutura em constante crescimento e mudança. Os componentes da parede celular são sintetizados e unidos entre si; e estruturas especializadas, como os séptos, são formados em sincronia com o crescimento e divisão celular. A parede celular das Saccharomyces sp. é formada por três componentes principais: glucana, um polímero de $\beta-1,3$ e $\beta-1,6$ glicose (48-60\%); mananaproteínas (20-23\%); e quitina, um polímero de $\beta$-1,4 N-acetilglucosamina (0,6-2,7\%) (KLIS, 1994). A composição desses polímeros, entretanto, é ajustável durante o ciclo celular e em resposta às condições ambientais, como: nutrientes, disponibilidade de $\mathrm{O}_{2}$, temperatura e $\mathrm{pH}$ (Cabib et al., 1997; KAPTEYN; van den ENDE; KLIS, 1999).

\subsection{Aplicação da $\beta-1,3$ glucanase purificada na lise de leveduras}

A Tabela 1 ilustra a atividade de lise de leveduras pela preparação purificada de $\beta-1,3$ glucanase. A lise das leveduras Saccharomyces cerevisiae KL-88, Saccharomyces capensis, Debaromyces vanriji, Pachysolen tannophillus, Kluyveromyces drosophilarum, Candida glabrata, Hansenula mrakii e Pichia membranaefaciens, utilizando $0,1 \mathrm{U}$ de $\beta-1,3$ glucanase purificada. $\mathrm{mL}^{-1}$ de suspensão celular, aumentou gradativamente com o aumento do tempo de exposição da levedura à enzima.

Após 3 horas de incubação com a $\beta-1,3$ glucanase purificada, as linhagens D. vanriji (52,96\% de lise), P. tannophillus $(100 \%$ de lise) e $H$. mrakii $(81,15 \%$ de lise) mostraram-se mais sensíveis à ação da $\beta-1,3$ glucanase purificada, enquanto que as linhagens S. cerevisiae KL-88 (15,12\% de lise), S. capensis ( $10,87 \%$ de lise) e C. glabrata ( $8,43 \%$ de lise) mostraram-se mais resistentes à ação da enzima. As linhagens $K$. drosophilarum e $P$. membranaefaciens apresentaram porcentagem relativa de lise de 20,64 e 21,93\%, respectivamente (Tabela 1).
Tabela 1. Estudo da lise de leveduras utilizando a $\beta-1,3$ glucanase purificada.

\begin{tabular}{lccc}
\hline \multicolumn{1}{c}{ Leveduras } & \multicolumn{3}{c}{ Tratamentos com $\beta$-1,3 glucanase } \\
\cline { 2 - 4 } & 1 hora (\%) & 2 horas (\%) & 3 horas (\%) \\
\hline S. cerevisiae KL-88 & 3,76 & 8,37 & 15,12 \\
S. capensis & 4,96 & 8,16 & 10,87 \\
D. vanriji & 28,62 & 28,14 & 52,96 \\
P. tannophillus & 89,97 & 91,35 & 100 \\
K. drosophilarum & 16,91 & 17,02 & 20,64 \\
C. glabrata & 5,67 & 6,37 & 8,43 \\
H. mrakii & 24,13 & 46,96 & 81,15 \\
P. membranaefaciens & 10,67 & 17,7 & 21,93 \\
\hline
\end{tabular}

Segundo Osumi (1998), a parede celular de Saccharomyces pombeécomposta principalmente de $\beta$-glucana e $\alpha$-galactomanana. Aguilar-Uscanga e François (2003) relatou a variabilidade da composição da parede celular de $S$. cerevisiae devido às diferentes condições de crescimento.

No presente trabalho, a $\beta-1,3$ glucanase purificada da linhagem C. cellulans 191 atuou diferentemente na lise das leveduras, provavelmente devido à diferença na composição da parede celular das leveduras.

Ao contrário do relato de outros trabalhos, este estudo mostrou também a lise de diferentes leveduras pela $\beta-1,3$ glucanase purificada de C. cellulans 191 sem a necessidade de protease lítica ou qualquer outro componente que degrade a camada de mananaproteína.

Guilloux-Benatier et al. (2000) estudaram a atividade de lise da $\beta-1,3$ glucanase produzida pela bactéria Oenococcus oeni sobre células de Saccharomyces cerevisiae em diferentes fases de crescimento. Os autores verificaram que a $\beta-1,3$ glucanase foi capaz de lisar células viáveis e mortas de $S$. cerevisiae, sendo que as células nas fases de crescimento exponencial e na fase estacionária foram lisadas mais facilmente. Kaneko, Kitamura e Yamamoto (1973) verificaram que as células de leveduras são mais susceptíveis à lise enzimática quando tratadas com 2-mercaptoetanol ou cisteína. O 2-mercaptoetanol exerce o papel de uma protease lítica, destruindo a camada externa de mananaproteína da parede celular e permitindo o acesso da $\beta-1,3$ glucanase à camada de glucana. A fração $\mathrm{A}$ da preparação comercial Zymolyase, composta por uma $\beta-1,3$ glucanase, é capaz de causar lise da parede celular de leveduras somente na presença de 2-mercaptoetanol.

A $\beta-1,3$ glucanase purificada da linhagem Cellulosimicrobium cellulans 191 de 45 KDa em SDS-PAGE (FLEURI; SATO, 2007) foi capaz de lisar extensivamente células viáveis das leveduras Debaromyces vanriji, Pachysolen tannophillus e Hansenula mrakii, sem a presença de protease. A enzima lisou, em menor proporção as leveduras Saccharomyces cerevisiae KL-88, Saccharomyces capensis, Kluyveromyces drosophilarum, Candida glabrata e Pichia membranaefaciens. A glucanase aqui relatada, possivelmente devido ao seu tamanho e ao seu arranjo tridimensional, pode ter atravessado a camada externa 
de mananaproteína, ter acessado a camada interna de glucana e provocado a lise celular.

\subsection{Aplicação da $\beta-1,3$ glucanase purificada na lise de leveduras - observação em microscópio óptico}

Na Figura 1a, b, c, e, g, i, k, m, o ilustram as células de leveduras em tampão fosfato $0,1 \mathrm{M}, \mathrm{pH} 6,5$ sem tratamento com $\beta-1,3$ glucanase purificada; enquanto que, na Figura $1 b, d, f, h, j$, $1, \mathrm{n}, \mathrm{p}$ ilustram as células de leveduras em tampão fosfato $0,1 \mathrm{M}$, $\mathrm{pH} 6,5$ tratadas com $0,1 \mathrm{U}$ de $\beta-1,3$ glucanase purificada. $\mathrm{mL}^{-1}$ de suspensão.

Verificou-se diminuição no número de células de leveduras, quando as leveduras foram tratadas com a $\beta-1,3$ glucanase purificada da linhagem Cellulosimicrobium cellulans 191, a $30{ }^{\circ} \mathrm{C}$ por 3 horas.

Estes resultados somados aos descritos anteriormente indicam que a $\beta-1,3$ glucanase purificada da linhagem C. cellulans 191 é capaz de lisar sozinha vários gêneros e espécies de leveduras, sem a presença de protease.

Shimoi et al. (1991) purificaram enzimas líticas produzidas por Rarobacter faecitabidus, uma bactéria capaz de lisar células de leveduras. As enzimas consistiram de uma $\beta-1,3$ glucanase (82 KDa em SDS-PAGE) e duas proteases ( 35 e $33 \mathrm{KDa}$ em SDS-PAGE). As proteases foram capazes de reduzir a turbidez de suspensões de leveduras, entretanto o número de células de leveduras não diminuiu sob observação ao microscópio. A $\beta-1,3$ glucanase não diminuiu a turbidez das suspensões de
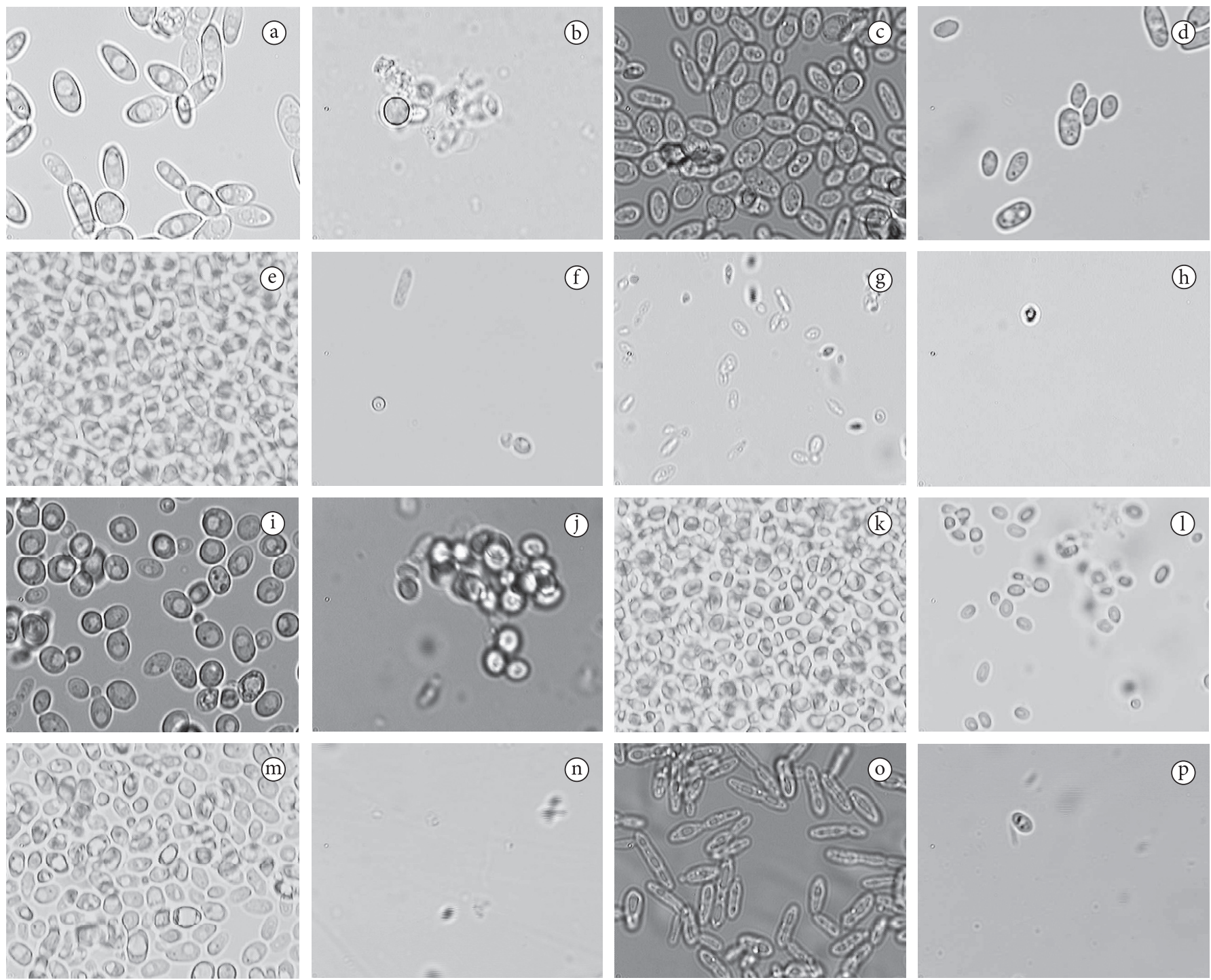

(P)

Figura 1. Lise de leveduras com $\beta-1,3$ glucanase purificada. Observação em microscópio óptico com aumento de 1000 vezes (imersão), sendo: a- Controle S. cerevisiae KL88; $b$ - S. cerevisiae KL88 tratada com $\beta-1,3$ glucanase purificada; c- Controle S. capensis; d- S. capensis tratada com $\beta-1,3$ glucanase purificada; e- Controle K. drosophilarum; f- K. drosophilarum tratada com $\beta-1,3$ glucanase purificada; g- Controle P. tannophillus; h- P. tannophillus tratada com $\beta-1,3$ glucanase purificada; i- Controle P. membranaefaciens; j- P. membranaefaciens tratada com $\beta$ - 1,3 glucanase purificada; k- Controle C. glabrata; l- C. glabrata tratada com $\beta-1,3$ glucanase purificada; m- Controle H. mrakii; n- H. mrakii tratada com $\beta$-1,3 glucanase purificada; o- Controle D. vanriji e p- D. vanriji tratada com $\beta-1,3$ glucanase purificada. 

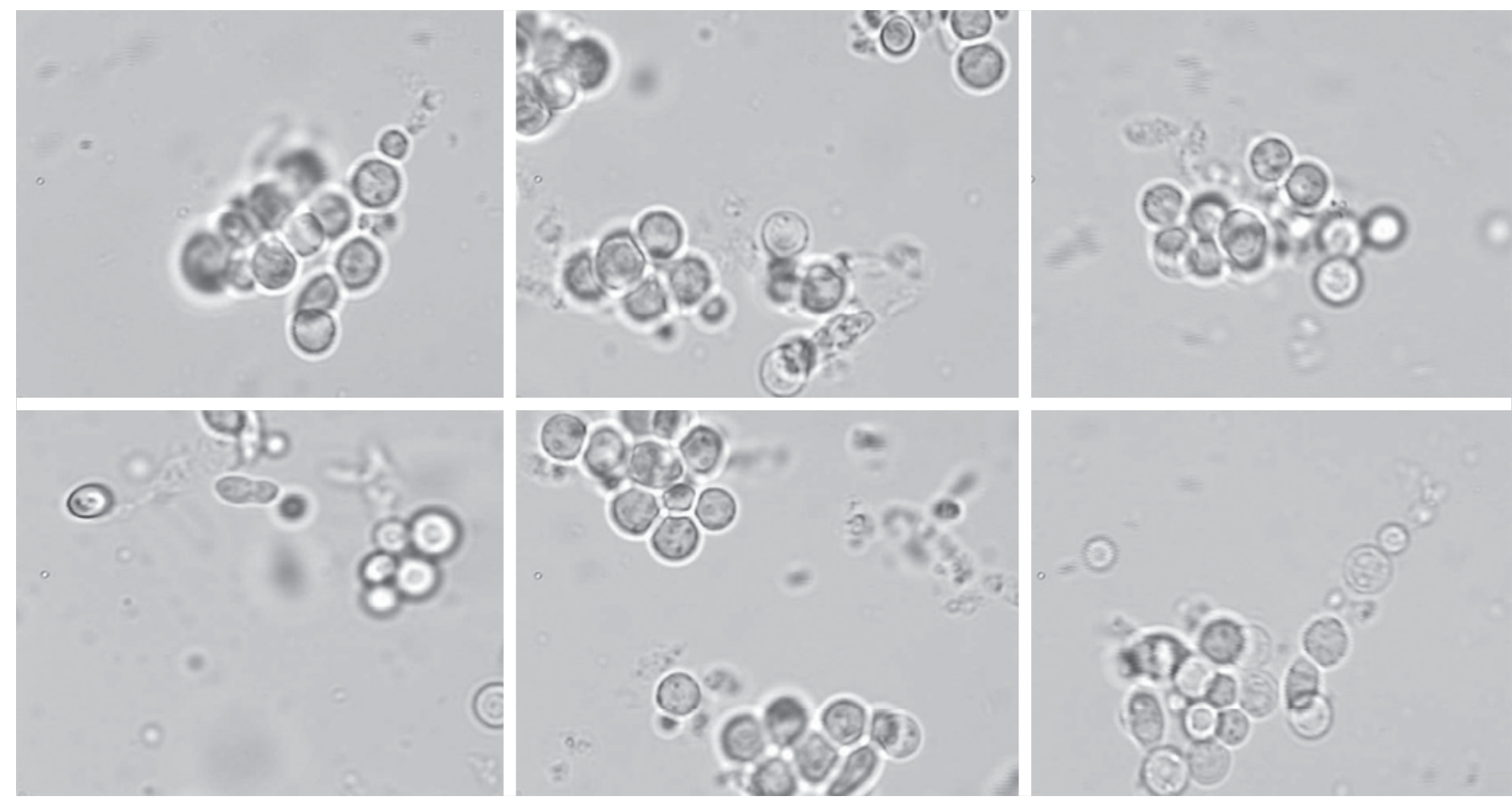

Figura 2. Protoplastos obtidos a partir de células de Saccharomyces cerevisiae KL-88 após ação da $\beta$-1,3 glucanase purificada da linhagem C. cellulans 191 - Observação em microscópio óptico com aumento de 1000 vezes (imersão).

leveduras, mas combinada com as duas proteases, lisaram as células de levedura completamente.

No presente estudo, a $\beta-1,3$ glucanase purificada ( $45 \mathrm{KDa}$ em SDS-PAGE) da linhagem Cellulosimicrobium cellulans 191 foi capaz de diminuir a turbidez de suspensões de células de leveduras e diminuir o número de células sob observação ao microscópio óptico.

\subsection{Aplicação da $\beta-1,3$ glucanase purificada na formação de protoplastos - observação em microscópio óptico}

A $\beta-1,3$ glucanase purificada da linhagem C. cellulans 191 foi utilizada para a produção de protoplastos de $S$. cerevisiae KL88. A Figura 2 ilustra a formação de protoplastos da levedura em microscópio óptico com aumento de 1000 vezes (imersão), após a incubação das suspensões de leveduras a $30^{\circ} \mathrm{C}$ por 2 horas com $0,1 \mathrm{U}$ de $\beta-1,3$ glucanase purificada. $\mathrm{mL}^{-1}$ de suspensão.

As células de leveduras sem nenhum tratamento apresentam, sob observação em microscópio óptico, uma forma elipsoidal. O protoplasto é a célula desprovida da parede celular, envolta somente pela membrana plasmática e apresenta, sob observação em microscópio óptico, forma esférica. Portanto, a produção de protoplastos é verificada em microscópio óptico pela modificação da forma celular da levedura.

A preparação purificada de $\beta-1,3$ glucanase da linhagem C. cellulans 191 foi capaz de formar protoplastos de Saccharomyces cerevisiae KL-88 (Figura 2).

\section{Conclusões}

As preparações bruta e purificada da enzima lítica $\beta-1,3$ glucanase, obtida do microrganismo Cellulosimicrobium cellulans 191, foi capaz de lisar vários gêneros de leveduras. A enzima apresenta a capacidade de atravessar a camada externa de mananaproteína, acessar a camada interna de glucana, degradando-a e lisar células de leveduras. A $\beta-1,3$ glucanase apresenta um grande potencial de aplicação na lise de leveduras e formação de protoplastos e que pode ser estendido para a obtenção de diversos produtos intracelulares, polissacarídeos da parede celular e no controle de microrganismos patogênicos. As preparações enzimáticas bruta e purificada mostraram espectro de ação sobre vários gêneros e espécies de leveduras, ampliando o campo de utilização da $\beta-1,3$ glucanase.

\section{Referências bibliográficas}

AGUILAR-USCANGA, B.; FRANÇOIS, J. M. A study of the yeast cell wall composition and structure in response to growth conditions and mode cultivation. Letters in applied microbiology, v. 37, n. 3, p. 268, 2003.

ASENJO, J. A. et al. Microbial cell lytic enzyme systems: production and reaction kinetics. Process Biochemistry, p. 159-164, 1985.

CABIB, E. et al. The yeast cell wall, a dynamic structure engaged in growth and morphogenesis. Biochemistry Society Transactions, v. 25, n. 1, p. 200-204, 1997.

DOI, K.; DOI, A.; FUKUI, T. Heterogeneity of the lytic activity for yeast cell wall observed among the components of an arthrobacter glucanase. Agricultural Biological Chemistry, v. 37, n. 7, p. 1619-1627, 1973. 
FERRER, P. et al. Molecular cloning of a lytic 1,3 glucanase gene from Oerskovia xanthineolytica LLG109. Annals of the New York Academy of Sciences, v. 782, p. 555, 1996.

FERRO, L. A. Produção, purificação e caracterização da enzima $\beta-1,3$ glucanase de Cellulomonas cellulans YLM-B191-1 e ação da enzima na parede celular de leveduras. 175 p. Tese (Doutorado) - Universidade Estadual de Campinas, Campinas, 2002.

FLEURI, L. F. Produção de $\beta-\mathbf{1 , 3}$ glucanases, proteases líticas e quitinases por microrganismos e aplicação na lise de leveduras. 141 p. Dissertação (Mestrado) - Universidade Estadual de Campinas, Campinas, 2003.

FLEURI, L. F. $\boldsymbol{\beta}-1,3$ glucanases, proteases e quitinases: produção, purificação e aplicação. 213 p. Tese (Doutorado) - Universidade Estadual de Campinas, Campinas, 2006.

FLEURI, L. F.; SATO, H. H. Estudo da influência de diferentes parâmetros na produção de enzimas líticas. Ciência e Tecnologia de Alimentos, v. 28, n. 2, p.1-12, 2008.

FLEURI, L. F.; SATO, H. H. Produção, purificação, clonagem e aplicação de enzimas líticas. Quimica Nova, v. 28, n. 5, p. 871-879, 2005.

FLEURI, L. F.; SATO, H. H. $\beta-1,3$ glucanase. Biotecnologia: Ciência e Desenvolvimento, v. 37, p. 40-43, 2007.

FUNATSU, M. et al. Protease of Arthrobacter luteus, properties and functional on lysis of viable yeast cells. Agricultural Biological Chemistry, v. 42, n. 10, p. 1975-1977, 1978.

GUILLOUX-BENATIER, M. et al. Lysis of yeast cells by Oenococcus oeni enzymes. Journal of Industrial Microbiology and Biotechnology, v. 25, p. 193-197, 2000.

KANEKO, T.; KITAMURA, K.; YAMAMOTO, Y. Susceptibilities of yeasts to yeast cell wall lytic enzyme of Arthrobacter luteus. Agricultural Biological Chemistry, v. 37, n. 10, p. 2295-2302, 1973.

KAPTEYN, J. C.; van den ENDE, H.; KLIS, F. M. The contribution of cell wall proteins to the organization of the yeast cell wall. Biochimica et Biophysica Acta, v. 1426, n. 2, p. 373, 1999.

$\mathrm{KIM}, \mathrm{S}$. Y. et al. Biomedical issues of dietary fiber $\beta$-glucan. Journal of Korean Medical Science, v. 21, n. 10, p. 781-789, 2006.
KITAMURA, K. A high yeast cell wall lytic enzyme - producing mutant of Arthrobacter luteus. Journal of Fermentation Technology, v. 60, n. 3, p. 253-256, 1982.

KLIS, F. M. Review: cell wall assembly in yeast. Yeast, v. 10, p. 851-869, 1994.

OBATA, T. et al. Synergistic effects among $\beta-1,3$ glucanase from Oerskovia sp CK. on lysis of viable yeast cell. Agricultural Biological Chemistry, v. 41, n. 12, p. 671-677, 1977.

OSUMI, M. The ultrastructure of yeast: cell wall structure and formation. Micron and Microscopica Acta, v. 29, n. 6, p. 207-233, 1998.

SALAZAR, O.; ASENJO, J. A. Enzymatic lysis of microbial cells. Biotecnhology Letters, v. 29, p. 984-994, 2007.

SANTOS, L. F. Produção, purificação, caracterização e estudo da aplicação de uma protease alcalina produzida por Cellulosimicrobium cellulans 191. 97 p. Tese (Doutorado) Universidade Estadual de Campinas, Campinas, 2004.

SCOTT, J. H.; SCHEKMAN, R. Lyticase: endoglucanase and protease activities that act together in yeast cell lysis. Journal Bacteriology, v. 142 , n. 2, p. 414-423, 1980.

SHIMOI, H. et al. Purification of the enzymes responsible for the lysis of yeast cell by rarobacter faecitabidus. Agricultural Biological Chemistry, v. 55, p. 371-378, 1991.

SOARES, G. A. M. Enzimas que lisam a parede celular de leveduras - clonagem e sequenciamento do gene da $\beta$-1,3 glucanase lítica de Cellulomonas cartae 191. 113p. Tese (Doutorado) - Universidade Estadual de Campinas, Campinas, 2002.

VENTOM, A. M.; ASENJO, J. A. Characterization of yeast lytic enzymes from Oerskovia xanthineolytica LL-G109. Enzymes Microbial Technology, v. 13, p. 71-75, 1991.

YAMAGUCHI, M. M. Seleção, produção e caracterização da enzima quitinase. 83 p. Tese (Doutorado) - Universidade Estadual de Campinas, Campinas, 2003.

ZLOTNIK, H. et al. Saccharomyces cerevisiae mannoproteins from an external cell wall layer that determines wall porosity. Journal of Bacteriology, v. 159, n. 3, p. 1018-1026, 1984. 